\title{
Impact of supported ionic liquids on supported Pt catalysts
}

\author{
Richard Knapp, Andreas Jentys and Johannes A. Lercher
}

Lehrstuhl II für Technische Chemie, Technische Universität München, Lichtenbergstr. 4,

D-85747 Garching, Germany

\begin{abstract}
Silica supported platinum catalysts coated with a thin film of 1-butyl-2,3-dimethylimidazolium trifluoromethane sulphonate $(\mathrm{BDiMIm})$ were investigated with respect to the interactions of the ionic liquid with the oxide support and the metal clusters. IR, inelastic neutron scattering and NMR spectroscopy indicate that the vibrations of the imidazolium ring of ionic liquid are less restricted when supported on $\mathrm{SiO}_{2}$, while the viscosity of the supported ionic liquid increased. The presence of Pt particles enhances the electron density of the ionic liquid at the nitrogen atom inducing higher basicity. The coverage of the catalyst surface and the metal particles by the ionic liquid protects the metal against oxidation. The catalysts are active and stable for hydrogenation of ethene.
\end{abstract}

Keywords: ionic liquids, supported catalysts, platinum, EXAFS, INS, MAS NMR 


\section{Introduction}

To combine the high diversity and homogeneity of molecular catalysts with the facile separation of solid catalysts the immobilization of organometallic complexes in thin films of supported ionic liquid has been proposed as new concept. ${ }^{1,2,3}$ As such, immobilizing an organic $^{4}$ or aqueous phase ${ }^{5}$ on a support surface has already been described in 1990. The major drawback of these catalysts, however, has been that the liquid film is volatile, which limits the application at high temperatures. In addition, the stability of the catalytically active component in the aqueous phase is often insufficient.

An alternative are the recently introduced supported ionic liquid catalysts, prepared by impregnation of a porous material with an ionic liquid. ${ }^{6}$ The catalytically active components are immobilized in the ionic liquid and due to its the low vapor pressure these catalysts can be applied in gas phase reactions. ${ }^{7}$ The properties of the supported catalysts can be fine-tuned by optimizing the type of ionic liquid and of the metal component. In particular, the solubility and, thus, the selectivity for different reactants can be improved by selecting the polarity of the ionic liquid. The interaction between the ionic liquid and the active component is complex showing ordering phenomena and domain formation of the ionic liquid. ${ }^{8,9}$ Catalysts with immobilized ionic liquids were successfully used in reactions like hydroformylation of olefins ${ }^{1}$, achiral hydrogenation ${ }^{10}$, Heck-reaction ${ }^{11}$ and hydroamination. ${ }^{2,3}$

This work is focused on the synthesis and characterization of catalysts based on ionic liquid mediated metal nanoparticles, which allows combining different functionalities in a single material as co-catalysts and/or stabilizing agents can be easily added into the ionic liquid phase. As active component Pt metal clusters were immobilized in supported thin films of 1-butyl-2,3-dimethyl-imidazolium trifluoromethane sulphonate. Key properties for the application as catalysts such as accessibility, mobility and local environment of the metal clusters were studied with a particular focus on the interaction between metal clusters and ionic liquids. The schematic drawing of the catalysts explored is depicted in Fig. 1. 


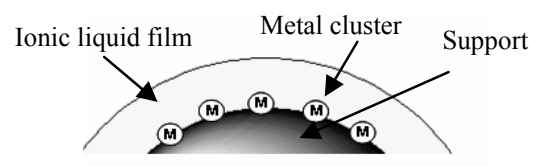

Fig. 1 Catalyst concept with metal clusters immobilized in thin films of ionic liquid

\section{Experimental}

\subsection{Materials}

The ionic liquid 1-butyl-2,3-dimethyl-imidazolium trifluoromethane sulphonate (BDiMIm) (99\%) with a maximum water and halide content of 47.8 and $103.1 \mathrm{ppm}$, respectively, was kindly provided by Solvent Innovation GmbH. Chloroplatinic acid hexahydrate (Pt content $\geq 37.5 \%$ ) and methanol (99.8\%) were obtained from Aldrich. Octane $(>99 \%)$ was purchased from Fluka. All chemicals were used as received. The silica support Aerosil 355 was provided by Degussa AG. For INS measurements $\mathrm{SiO}_{2}-60$ from Chemie AG was used.

\subsection{Preparation of the supported catalysts}

The silica support was ground, sieved to $100 \mu \mathrm{m}$ particle size and dried at $200{ }^{\circ} \mathrm{C}$. Catalysts with immobilized metal clusters ( $1 \mathrm{wt} \%$ metal) were prepared by incipient wetness impregnation. Chloroplatinic acid hexahydrate was dissolved in the appropriate amount of bi-distilled water; the solution was trickled onto the support and stirred until the water was completely absorbed. The water was removed by freeze drying. The precursors were calcined at $400{ }^{\circ} \mathrm{C}$ for three hours in synthetic air and subsequently reduced at $250{ }^{\circ} \mathrm{C}$ for three hours in a flow of hydrogen.

For preparing the supported ionic liquid catalysts $\mathrm{Pt} / \mathrm{SiO}_{2}$ was added to a solution of BDiMIm dissolved in methanol. The suspension was stirred at room temperature for $10 \mathrm{~min}$ and the volatile components were slowly removed by freeze drying to give a free flowing grey powder $\left(\mathrm{Pt} / \mathrm{BDiMIm} / \mathrm{SiO}_{2}\right)$.

A silica supported ionic liquid was prepared by adding $\mathrm{SiO}_{2}$ into a solution of BDiMIm dissolved in methanol. After stirring for $10 \mathrm{~min}$, the suspension was freeze dried to give a free flowing white powder $\left(\mathrm{BDiMIm} / \mathrm{SiO}_{2}\right)$. 


\subsection{Characterization}

The platinum content of the supported catalysts was determined by AAS using a UNICAM 939 spectrometer. The amount of ionic liquid adsorbed on the surface was determined by elemental analysis.

The IR spectra were measured on a Bruker IFS 88 spectrometer in transmission mode. The samples were pressed into self-supporting wafers and activated in vacuum for $1 \mathrm{~h}$ at $150^{\circ} \mathrm{C}$. Pt containing samples were reduced in-situ at $250^{\circ} \mathrm{C}$ and 0.8 bar hydrogen for 30 minutes. The spectra were recorded at a resolution of $4 \mathrm{~cm}^{-1}$ in the region from 4000 to $400 \mathrm{~cm}^{-1}$. To compare the different samples, the spectra of the activated samples were normalized using the overtone and combination vibrations of silica between 2105 and $1740 \mathrm{~cm}^{-1}$. For IR measurements of the pure ionic liquid, a $\mathrm{KBr}$ wafer was pressed and analyzed using a Jasco FT/IR-460 Plus spectrometer.

INS-Experiments were carried out at $15 \mathrm{~K}$ at the Be-filter detector spectrometer IN1BeF at ILL in Grenoble using a $\mathrm{Cu}$ (220) monochromator. The instrument resolution was between $4 \mathrm{~cm}^{-1}$, at low energy transfers and $25 \mathrm{~cm}^{-1}$ at high energy transfers. The vibrational modes of the ionic liquid were calculated with GAUSSIANO3 ${ }^{12}$ and the INS spectra were calculated using a-CLIMAX. ${ }^{13}$

For solid state NMR, the samples were packed in $4 \mathrm{~mm} \mathrm{ZrO}_{2}$ rotors. ${ }^{1} \mathrm{H}$ MAS NMR measurements were performed on a Bruker AV500 spectrometer $\left(\mathrm{B}_{0}=14.1 \mathrm{~T}\right)$ with a spinning rate of $15 \mathrm{kHz}$. For temperature adjustment the bearing and drive gas stream were passed through a heat exchanger. The spectra were recorded as the sum of 100 scans using single pulse excitation with a pulse length of $2.6 \mu$ s and recycle time of $3 \mathrm{~s}$.

For transmission electron microscope images, the samples were grinded, suspended in octane and ultrasonically dispersed. Drops of the dispersions were applied on a coppergrid supported carbon film. Micrographs were recorded on a JEM-2010 Jeol transmission electron microscope operating at $120 \mathrm{kV}$.

The EXAFS spectra were collected at the beamline X1 at HASYLAB, DESY, Hamburg, Germany. The storage ring was operated at $4.5 \mathrm{GeV}$ with an average current of $100 \mathrm{~mA}$. The Si (311) double-crystal monochromator was detuned to $60 \%$ of the maximum intensity to minimize the intensity of higher harmonics in the X-ray beam. The 
catalysts were pressed into self supporting wafers (ca. $150 \mathrm{mg}$ ) and the X-ray absorption spectra were collected at the Pt $\mathrm{L}_{\mathrm{III}}$ edge $(11.564 \mathrm{eV})$ in a helium flow at liquid $\mathrm{N}_{2}$ temperature. The EXAFS data was analysed using the Viper software. ${ }^{14}$ For EXAFS analysis, the scattering contributions of the background were removed from the X-ray absorption by a third-order polynomial function. The oscillations were weighted with $\mathrm{k}^{2}$ and Fourier-transformed within the limit $\mathrm{k}=3.5-16 \AA^{-1}$. The local environment of the $\mathrm{Pt}$ atoms was determined from the EXAFS using the phase-shift and amplitude function for $\mathrm{Pt}-\mathrm{Pt}$ and $\mathrm{Pt}-\mathrm{O}$ calculated assuming multiple scattering processes (FEFF version $8.40){ }^{15,16}$

The XANES data were collected in a helium flow at room temperature and analysed using the XANES dactyloscope software. ${ }^{17}$ All recorded XANES spectra were normalized to unity. The position of the edge was calibrated using the spectra of a Pt reference-foil measured simultaneously.

\subsection{Catalytic activity}

The hydrogenation of ethylene was studied at temperatures between 30 and $50{ }^{\circ} \mathrm{C}$ with a hydrogen to ethylene ratio of $2.5: 1$ in a fixed bed reactor filled with $0.1 \mathrm{mg}$ catalyst (diluted with $\mathrm{SiO}_{2}$ and $\mathrm{SiC}$ ). The products were analyzed using a Shimadzu GC-2014 gas chromatograph.

\section{Results}

\subsection{Infrared spectroscopy}

The IR spectra of the catalysts and of the pure ionic liquid (prepared in $\mathrm{KBr}$ ) are shown in Fig. 2. With pure $\mathrm{SiO}_{2}$ support a sharp band at $3745 \mathrm{~cm}^{-1}$ and a broad band at $3600 \mathrm{~cm}^{-1}$ were observed, which are assigned to free and hydrogen bonded silanol groups. After depositing $\mathrm{Pt}$ on this silica support $\left(\mathrm{Pt} / \mathrm{SiO}_{2}\right)$ the intensity of the band for silanol groups decreased by $20 \%$. Upon adsorption of BDiMIm on $\mathrm{SiO}_{2}\left(\mathrm{BDiMIm} / \mathrm{SiO}_{2}\right)$ and on $\mathrm{Pt} / \mathrm{SiO}_{2}\left(\mathrm{Pt} / \mathrm{BDiMIm} / \mathrm{SiO}_{2}\right)$ the band corresponding to terminal $\mathrm{SiOH}$ groups disappeared and new bands at $3390 \mathrm{~cm}^{-1}\left(\mathrm{BDiMIm} / \mathrm{SiO}_{2}\right)$ and $3372 \mathrm{~cm}^{-1}$ $\left(\mathrm{Pt} / \mathrm{BDiMIm} / \mathrm{SiO}_{2}\right)$ were observed. All other bands observed in these spectra are attributed to the ionic liquid. 
Symmetric and asymmetric stretching vibrations of $=\mathrm{CH}$ groups appear at 3184 and $3142 \mathrm{~cm}^{-1}$, C-H stretching vibrations of methylen and methyl groups give absorption bands at 2967 and $2941 \mathrm{~cm}^{-1}$ and the methyl amino group was observed at $2878 \mathrm{~cm}^{-1}$. At 1589 and $1538 \mathrm{~cm}^{-1} \mathrm{C}=\mathrm{C}$ stretching vibrations and at 1434,1423 and $1388 \mathrm{~cm}^{-1} \mathrm{C}-\mathrm{H}$ bending vibrations were observed. For the ionic liquid prepared in $\mathrm{KBr}$ bands at 2000, 1890 and $1645 \mathrm{~cm}^{-1}$ were observed assigned to ring deformation vibrations and stretching vibrations of $\mathrm{C}=\mathrm{N}$.

After immobilization of the ionic liquid on $\mathrm{SiO}_{2}$ or $\mathrm{Pt} / \mathrm{SiO}_{2}$ the bands at $2975 \mathrm{~cm}^{-1}$ (C-H stretching) and $1473 \mathrm{~cm}^{-1}$ (C-H bending) were shifted to lower wavenumbers (2968 and $1466 \mathrm{~cm}^{-1}$ ) compared with the ionic liquid prepared in $\mathrm{KBr}$.

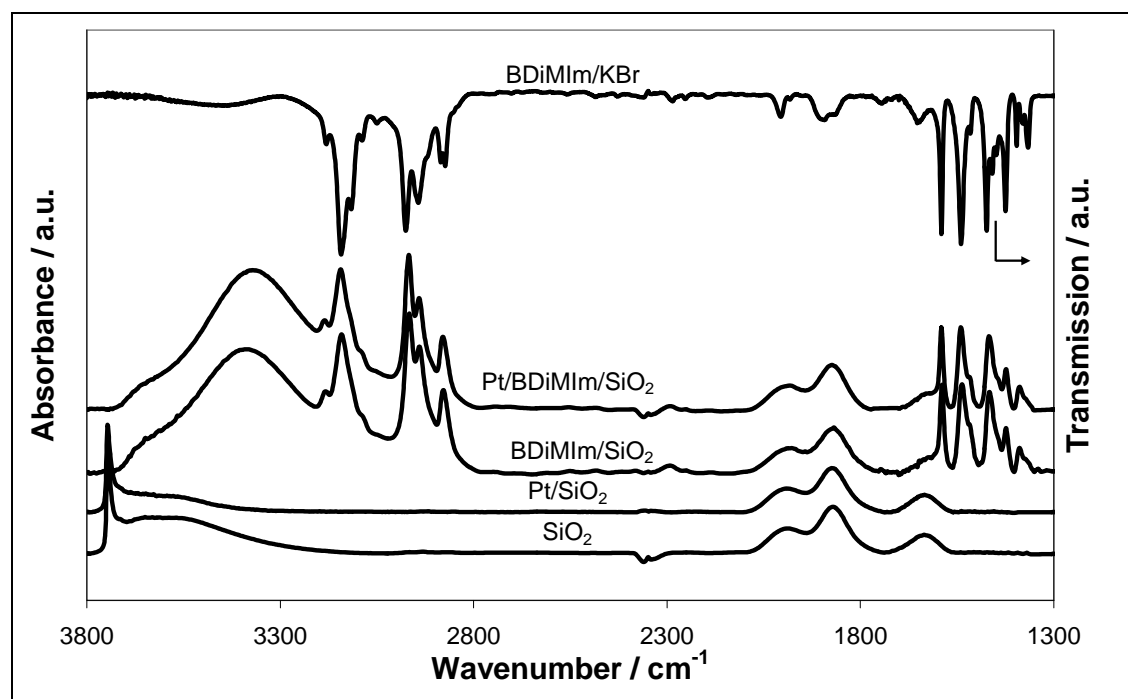

Fig. 2 IR absorption spectra of the silica support, platinum supported on silica, ionic liquid supported on silica and ionic liquid supported on $\mathrm{Pt} / \mathrm{SiO}_{2}$ and IR transmission spectrum of the ionic liquid in $\mathrm{KBr}$

\subsection{Inelastic neutron scattering}

The INS spectra of pure BDiMIm, BDiMIm supported on $\mathrm{SiO}_{2}$ and BDiMIm supported on $\mathrm{Pt} / \mathrm{SiO}_{2}$ are shown in Fig. 3. The bands at $580 \mathrm{~cm}^{-1}, 725 \mathrm{~cm}^{-1}$ and $1050 \mathrm{~cm}^{-1}$ increased when BDiMIm is supported on $\mathrm{SiO}_{2}$ or on $\mathrm{Pt} / \mathrm{SiO}_{2}$. The bands at $580 \mathrm{~cm}^{-1}$ and $1050 \mathrm{~cm}^{-1}$ were assigned to ring deformation vibrations of the imidazolium ring, the band at $725 \mathrm{~cm}^{-1}$ to out of plane vibrations $-\mathrm{CH}$ groups of the $\mathrm{C}_{5}$-ring. For the supported ionic liquids the band at $580 \mathrm{~cm}^{-1}$ was shifted to $610 \mathrm{~cm}^{-1}$. Furthermore, the intensities of the 
bands attributed to ring deformation vibrations were slightly higher when the ionic liquid was supported on $\mathrm{SiO}_{2}$ compared to the immobilization on $\mathrm{Pt} / \mathrm{SiO}_{2}$.

For pure BDiMIm the intensities of the bands at 490 and $880 \mathrm{~cm}^{-1}$, which were assigned to the in plane vibrations of the alkyl rests and stretching vibrations of the methylene groups of the butyl chain were higher compared to the supported ionic liquid. This indicates that the ring deformation led to a slightly higher relative movement of the hydrogen atoms, while the in plane movements of the alkyl rest is more constrained (less moving) than in the free ionic liquid.

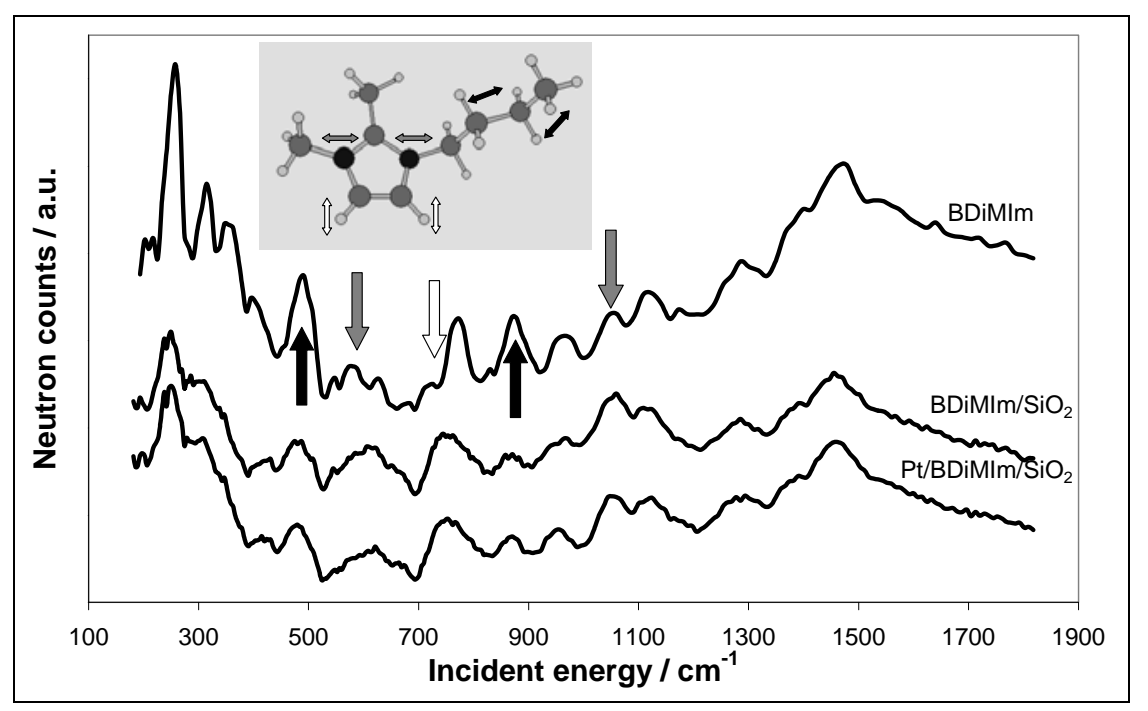

Fig. 3 INS spectra of ionic liquid, ionic liquid supported on silica and supported ionic liquid on $\mathrm{Pt} / \mathrm{SiO}_{2}$

\section{3 ${ }^{1}$ H MAS NMR Spectroscopy}

In the ${ }^{1} \mathrm{H}$ MAS NMR spectra of the ionic liquid immobilized on silica (Fig. 4) a noticeable line broadening was observed relative to the pure ionic liquid (for assignments see Table 1). The highest increase in line width was observed for the peaks assigned to the methylene group at the nitrogen atoms, while the smallest line broadening was observed for the terminal methyl and methylene groups of the alkyl chain. After temperature increase to $50^{\circ} \mathrm{C}$ and $70^{\circ} \mathrm{C}$, the line-width was further reduced and a high-field shift of the peak assigned to the protons of imidazolium ring was observed. This peak was also shifted by the same value $(0.1 \mathrm{ppm})$ when the ionic liquid was 
supported on $\mathrm{Pt} / \mathrm{SiO}_{2}$. However, differences in line-width were not observed when BDiMIm was supported on $\mathrm{Pt} / \mathrm{SiO}_{2}$ compared to $\mathrm{BDiMIm} / \mathrm{SiO}_{2}$.

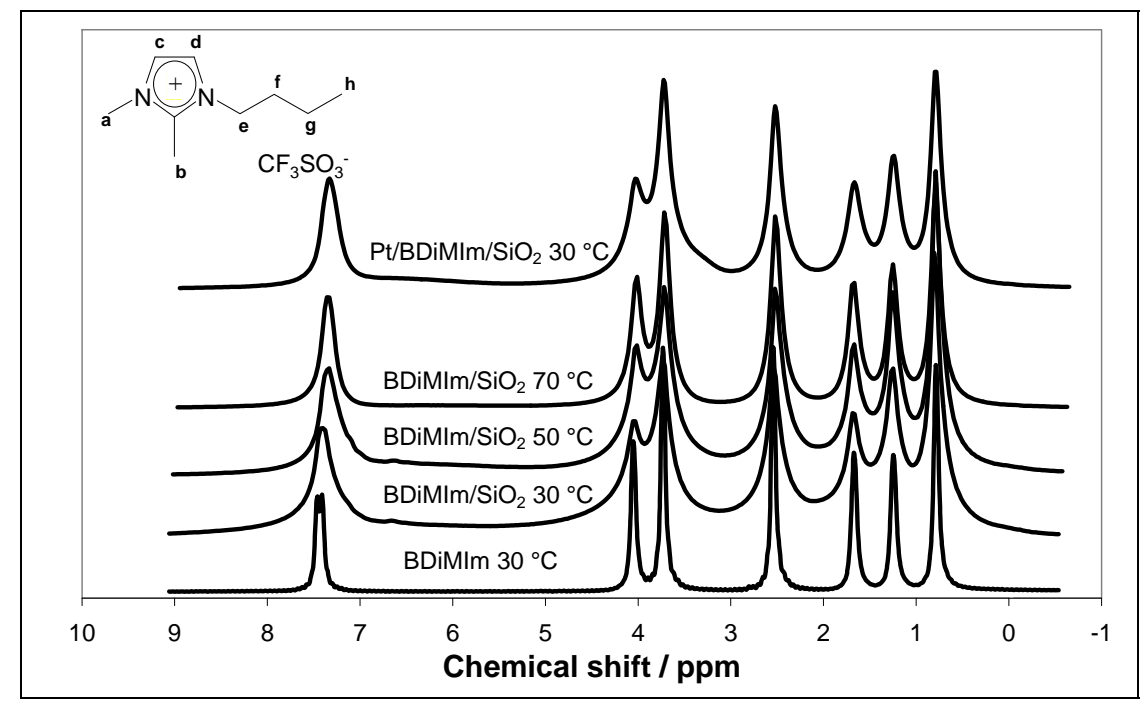

Fig. 4 Solid state ${ }^{1} \mathrm{H}$ NMR spectra of pure BDiMIm, BDiMIm/SiO $/ \mathrm{S}_{2}$ at different temperatures and $\mathrm{Pt} / \mathrm{BDiMIm} / \mathrm{SiO}_{2}$

Table 1 NMR peak assignment and full width at half maximum for pure BDiMIm, BDiMIm/ $/ \mathrm{SiO}_{2}$ at different temperatures and $\mathrm{Pt} / \mathrm{BDiMIm} / \mathrm{SiO}_{2}(\mathrm{CS}$ chemical shift / ppm; $\mathrm{LW}$ line-width / $\mathrm{Hz}$ )

\begin{tabular}{cccccc}
\hline & BDiMIm & \multicolumn{3}{c}{$\mathrm{BDiMIm} / \mathrm{SiO}_{2}$} & $\mathrm{Pt} / \mathrm{BDiMIm} / \mathrm{SiO}_{2}$ \\
\hline \multirow{2}{*}{ Assignment } & $30{ }^{\circ} \mathrm{C}$ & $30{ }^{\circ} \mathrm{C}$ & $50{ }^{\circ} \mathrm{C}$ & $70{ }^{\circ} \mathrm{C}$ & $30{ }^{\circ} \mathrm{C}$ \\
\cline { 2 - 6 } & $\mathrm{CS}(\mathrm{LW})$ & $\mathrm{CS}(\mathrm{LW})$ & $\mathrm{CS}(\mathrm{LW})$ & $\mathrm{CS}(\mathrm{LW})$ & $\mathrm{CS}(\mathrm{LW})$ \\
\hline $\mathrm{c}$ & $7.46(25)$ & $7.40(152)$ & $7.34(119)$ & $7.35(86)$ & $7.32(145)$ \\
$\mathrm{d}$ & $7.41(27)$ & & & & \\
$\mathrm{e}$ & $4.05(30)$ & $4.05(125)$ & $4.02(102)$ & $4.02(82)$ & $4.02(124)$ \\
$\mathrm{a}$ & $3.73(27)$ & $3.73(101)$ & $3.72(85)$ & $3.71(73)$ & $3.72(95)$ \\
$\mathrm{b}$ & $2.54(27)$ & $2.53(101)$ & $2.52(82)$ & $2.51(76)$ & $2.52(90)$ \\
$\mathrm{f}$ & $1.67(33)$ & $1.67(108)$ & $1.67(106)$ & $1.68(77)$ & $1.66(104)$ \\
$\mathrm{g}$ & $1.24(35)$ & $1.25(104)$ & $1.25(80)$ & $1.25(70)$ & $1.24(101)$ \\
$\mathrm{h}$ & $0.78(30)$ & $0.80(81)$ & $0.78(71)$ & $0.79(65)$ & $0.79(79)$ \\
\hline
\end{tabular}

\subsection{Transmission electron microscopy}

The TEM pictures of Pt clusters supported on silica and coated with $17 \mathrm{wt} \%$ ionic liquid at a magnification of 200.000 are shown in Fig. 5a and the particle size distribution, which indicates a mean metal particle size of $2.1 \mathrm{~nm}$ is shown in Fig. $5 b$. 


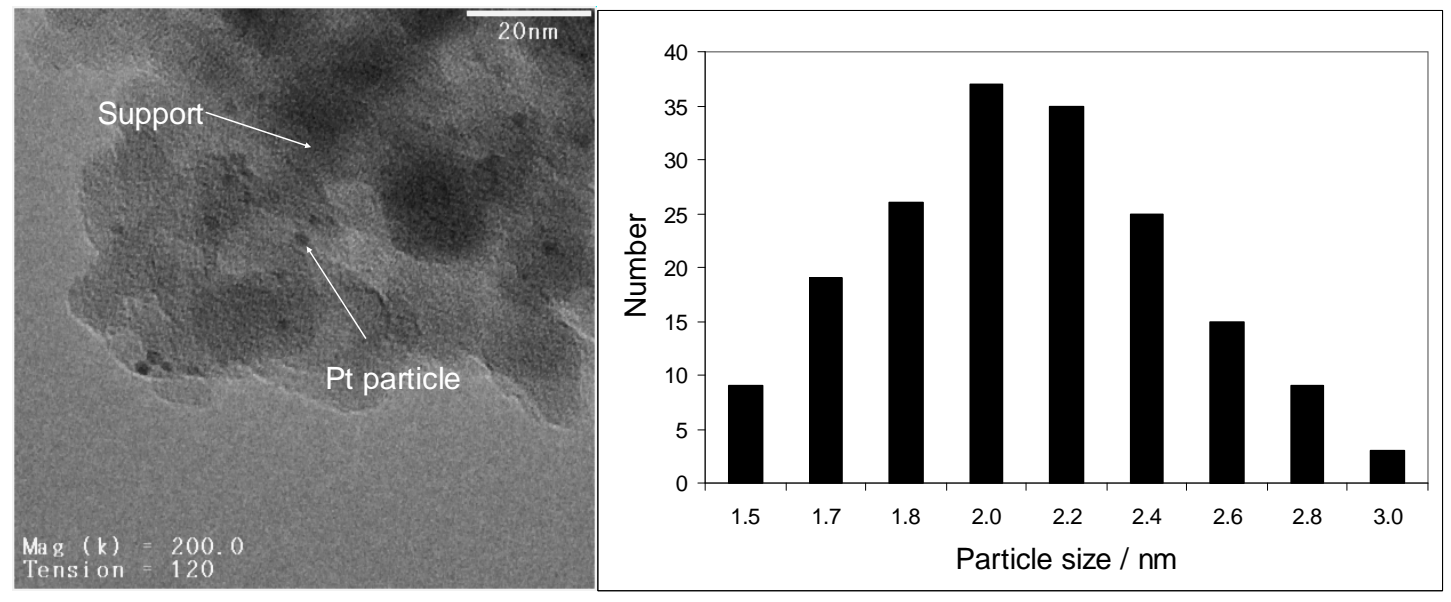

Fig. 5 TEM picture (a) and particle size distribution (b) of an ionic liquid coated supported platinum catalyst

\subsection{X-ray absorption near edge structure and extended X-ray absorption fine structure}

To determine the influence of the ionic liquid on electronical structure of the metal clusters $\mathrm{Pt} / \mathrm{SiO}_{2}$ and $\mathrm{Pt} / \mathrm{BDiMIm} / \mathrm{SiO}_{2}$, coated with $17 \mathrm{wt} \%$ of BDiMIm, were investigated by XANES and EXAFS.

The X-ray absorption spectra at the $\mathrm{L}_{\mathrm{III}}$ edge (shown in Fig. 6) show that the intensity of the peak above the edge is higher for the $\mathrm{Pt} / \mathrm{SiO}_{2}$ catalyst compared to $\mathrm{Pt} / \mathrm{BDiMIm} / \mathrm{SiO}_{2}$ and the Pt-reference foil.

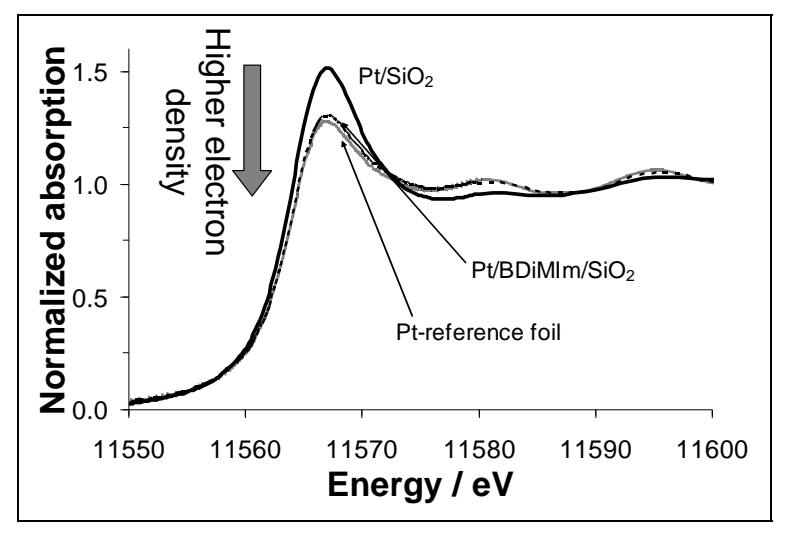

Fig. 6 XANES of an uncoated catalyst $\left(\mathrm{Pt} / \mathrm{SiO}_{2}\right)$, a coated catalyst $\left(\mathrm{Pt} / \mathrm{BDiMIm} / \mathrm{SiO}_{2}\right)$ and a Pt foil 
Fig. 7 compiles the Fourier-transformed EXAFS of the uncoated (Fig. 7a) and the coated catalyst (Fig. 7b). The number neighbours (coordination number $\mathrm{CN}$ ), their distance $(r)$, the Debye-Waller factor $\left(\sigma^{2}\right)$ and the zero energy correction $\left(E_{0}\right)$ were calculated from the EXAFS and are shown in Table 2. The results indicate that oxygen neighbouring atoms can only be found for the uncoated catalyst. Also the coordination number for Pt neighbouring atoms was half compared with the coated catalyst.
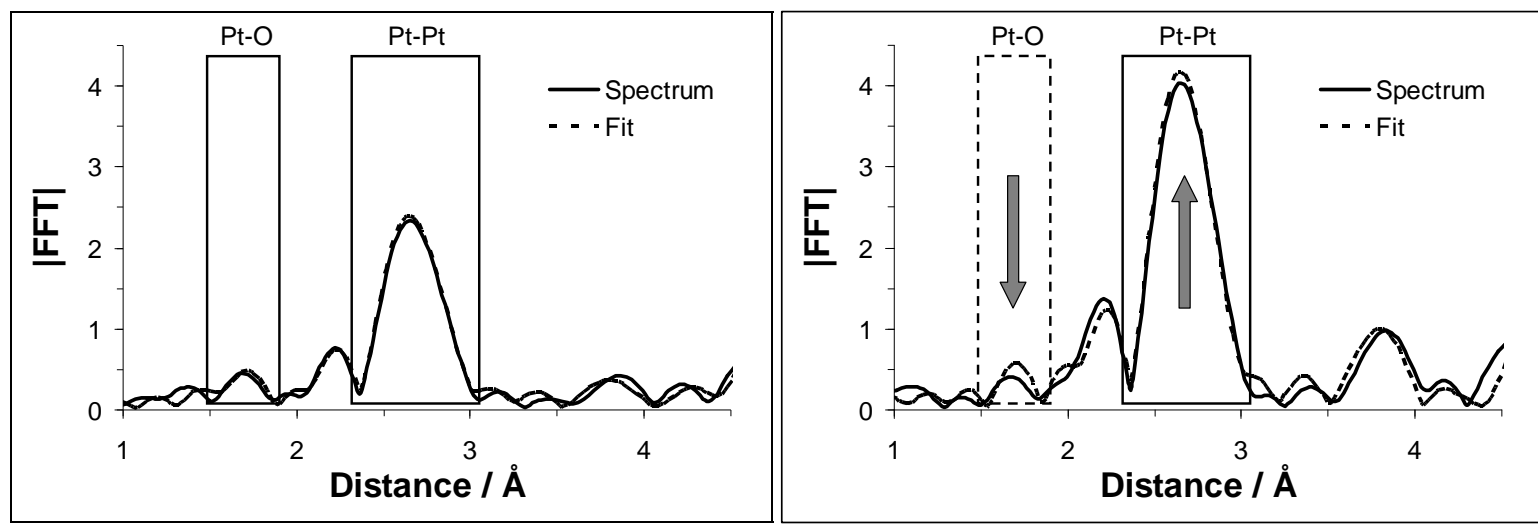

Fig. 7 Measured and calculated Fourier-transformed EXAFS of $\mathrm{Pt} / \mathrm{SiO}_{2}$ (a) and $\mathrm{Pt} / \mathrm{BDiMIm} / \mathrm{SiO}_{2}$ (b)

Table 2 EXAFS curve fitting results for $\mathrm{Pt} / \mathrm{SiO}_{2}$ and $\mathrm{Pt} / \mathrm{BDiMIm} / \mathrm{SiO}_{2}$

\begin{tabular}{ccc}
\hline & $\mathrm{Pt} / \mathrm{SiO}_{2}$ & $\mathrm{Pt} / \mathrm{BDiMIm} / \mathrm{SiO}_{2}$ \\
\hline $\mathrm{r}_{\mathrm{PtO}}[\AA]$ & 2.05 & 2.15 \\
$\mathrm{CN}_{\mathrm{Pt}-\mathrm{O}}$ & 0.81 & 0.0 \\
$\sigma^{2}$ & 0.0021 & 0.01619 \\
$\mathrm{E}_{0}[\mathrm{eV}]$ & 16.18 & 18.47 \\
\hline $\mathrm{r}_{\mathrm{PtPt}}[\AA]$ & 2.77 & 2.76 \\
$\mathrm{CN}_{\mathrm{Pt}-\mathrm{Pt}}$ & 4.4 & 8.9 \\
$\sigma^{2}$ & 0.0033 & 0.0033 \\
$\mathrm{E}_{0}[\mathrm{eV}]$ & 13.23 & 10.98 \\
\hline
\end{tabular}

The particle size was determined from the average coordination number of the nearest metallic neighboring atoms assuming cuboctahedral geometry. ${ }^{18}$ For $\mathrm{Pt} / \mathrm{SiO}_{2}$ the particle size was $0.9 \mathrm{~nm}$, corresponding to a dispersion of 0.9 and for $\mathrm{Pt} / \mathrm{BDiMIm} / \mathrm{SiO}_{2}$ a particle size of $1.95 \mathrm{~nm}$ was determined indicating a dispersion of 0.6. 


\subsection{Catalytic hydrogenation of ethene}

The activity of the uncoated and coated catalysts as function of the temperature is shown in Fig. 8. The reaction was zero order with respect to ethylene. The activation energy $42 \mathrm{~kJ} / \mathrm{mol}$ and $40 \mathrm{~kJ} / \mathrm{mol}$, respectively, was calculated using rates from experiments with a conversion below $25 \%$. (Note that for reactions with 0 order there is no difference between rates determined by a differential and integral analysis). The stability of the coated catalyst was followed at $70{ }^{\circ} \mathrm{C}$ after the series of kinetic experiments carried out up to $90{ }^{\circ} \mathrm{C}$, showing a constant rate over 36 hours.

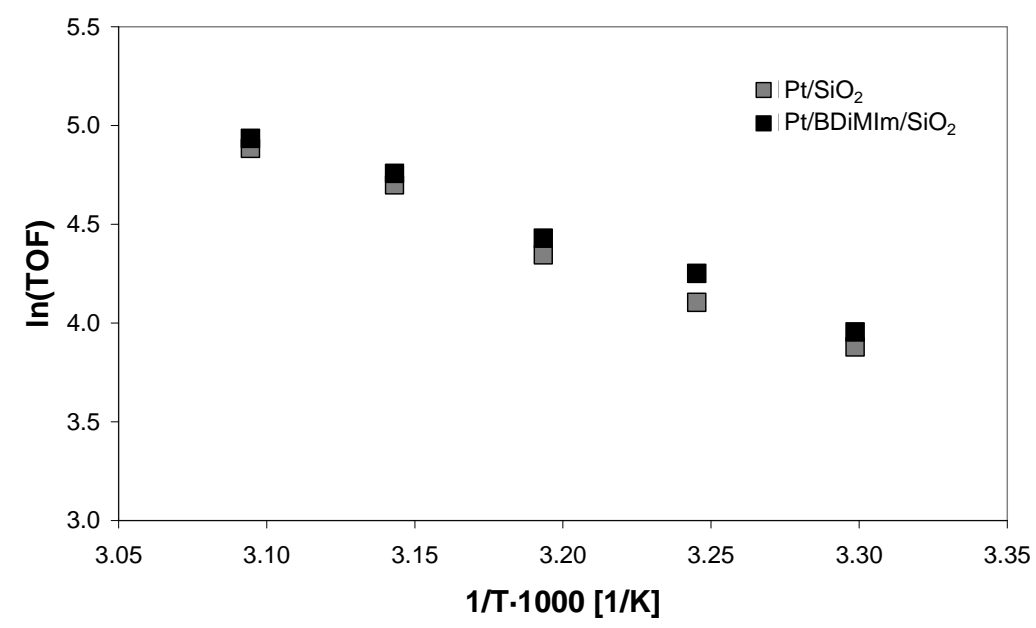

Fig. 8 Catalytic activities for $\mathrm{Pt} / \mathrm{SiO}_{2}$ and $\mathrm{Pt} / \mathrm{BDiMIm} / \mathrm{SiO}_{2}$

\section{Discussion}

Supported ionic liquids have been concluded to assume relative ordered states in the presence of metal organic complexes. ${ }^{9}$ The exact degree of coordination of the ions to the dissolved and suspended substrates are unknown, but the question arises whether or not such phenomena are confined solely to metal complexes and particles or if reacting molecules would also induce locally such phenomena, when dissolved in an IL. The most important feature of such ordering phenomena for catalysis is not the overall long range ordering, but the direct interactions determining the critical properties as sorbent and catalyst. Thus, we focus in the present case on the characterization of the interactions between the ionic liquid, the support and the Pt particles using molecular spectroscopy. 
For Pt on silica the intensity of the band characteristic for $\mathrm{SiOH}$ groups decreased by $20 \%$ compared with the silica before impregnation. On first sight this may be attributed to dehydration of $\mathrm{SiO}_{2}$ during the activation and reduction in hydrogen, since the treatment of $\mathrm{SiO}_{2}$ at the same conditions $\left(\mathrm{pH}, \mathrm{Cl}^{-}\right.$concentration and temperature) lead to a similar result. However, it is striking that the perturbed $\mathrm{OH}$ bands (indicating hydrogen bonding between $\mathrm{OH}$ groups) are affected most. This indicates that the Pt particles are preferentially anchored at sites with a higher $\mathrm{SiOH}$ concentration, i.e., at parts of the support containing more defects. In contrast, the decrease of the band of the unperturbed free $\mathrm{SiOH}$ groups at $3740 \mathrm{~cm}^{-1}$ was relative small suggesting that the role of these $\mathrm{OH}$ groups in the anchoring of the Pt particles is negligible.

The disappearance of the band of terminal $\mathrm{SiOH}$ groups after coating $\mathrm{SiO}_{2}$ with the ionic liquid indicates the complete coverage of the silica surface. The appearance of a new band at $3390 \mathrm{~cm}^{-1}$ for $\mathrm{BDiMIm} / \mathrm{SiO}_{2}$ and $3372 \mathrm{~cm}^{-1}$ for $\mathrm{Pt} / \mathrm{BDiMIm} / \mathrm{SiO}_{2}$ characteristic of perturbed $\mathrm{OH}$ vibrations led us to conclude that the interactions between the ionic liquid film and the silica occurred via hydrogen bonds. The difference of $18 \mathrm{~cm}^{-1}$ between these two bands suggests slightly stronger hydrogen bonding when BDiMIm is supported on $\mathrm{Pt} / \mathrm{SiO}_{2}$. The reasons for this stronger interactions with the trifluoromethane sulphonate anions could be caused by the more pronounced interactions of 1-butyl-2,3-dimethyl-imidazolium cations with the metal particles. These interactions in turn allow a stronger coordination of anions to $\mathrm{OH}$ groups.

This conclusion is indirectly supported by the INS spectra. In these spectra the bands assigned to the deformation vibrations of the imidazolium ring increased in intensity. The increase in intensity is attributed to stronger relative displacements of the hydrogen atoms (stronger vibrations). The coordination of the basic $\mathrm{CF}_{3} \mathrm{SO}_{3}{ }^{-}$anions to the weakly acidic surface hydroxyl and the stronger interaction with the metal particle allows for a stronger displacement of the $\mathrm{C}-\mathrm{H}$ vibrations. The shift of the band at $580 \mathrm{~cm}^{-1}$ to $610 \mathrm{~cm}^{-1}$ is attributed to these interactions constraining the deformation vibration of the imidazolium ring.

The line broadening observed in the NMR spectra of the supported catalysts can be attributed to differences in the T2 relaxation time that are not affected by MAS-NMR and therefore, can be used to determine the mobility of specific atomic groups. ${ }^{19,20,21}$ The 
immobilization of the ionic liquid on the support leads to a lower mobility of the molecules and thus to an increased viscosity. Especially the methylene group of nitrogen bound alkyl chain is affected (also detected by INS), as the intensities of the bands ascribed to in plane vibrations of the alkyl rests $\left(490 \mathrm{~cm}^{-1}\right)$ decreased for the supported ionic liquid compared with the pure BDiMIm. Differences in line width were not observed when BDiMIm was supported on $\mathrm{Pt} / \mathrm{SiO}_{2}$ compared to $\mathrm{BDiMIm} / \mathrm{SiO}_{2}$, since the amount of $1 \mathrm{wt} \%$ of $\mathrm{Pt}$ on the surface is not enough to cause a further increase in viscosity. However, for a sample with a metal loading of $5 \mathrm{wt} \%$ a noticeable line broadening was observed (results not reported here). After temperature increase, the line-width was reduced, as the mobility of the molecules increased due to the thermal energy. The peak assigned to the protons of the imidazolium shifted to a higher field after increasing the temperature.

In line with IR and INS, the 1H MAS-NMR spectra show that upon immobilization of the ionic liquid on $\mathrm{Pt} / \mathrm{SiO}_{2}$ the protons of the imidazolium shifted to a higher field compared to the IL support only on $\mathrm{SiO}_{2}$. This is attributed to an increased electron density of the imidazolium ring leading to a higher shielding of the protons. As the hydrogen bonds between the ionic liquid and the surface of the support occur via $\mathrm{CF}_{3} \mathrm{SO}_{3}{ }^{-}$anions, the stronger bonding of the imidazolium ring to $\mathrm{Pt}$, the higher the availability and base strength of the anion will be.

For the sample with $1 \mathrm{wt} \%$ metal loading TEM revealed that the particles were highly dispersed and that agglomerates of the metal clusters were not formed. The particle size determined by transmission electron microscopy $(2.1 \mathrm{~nm})$ was in good agreement with the particle size calculated from the EXAFS data $(1.95 \mathrm{~nm})$. The comparison of the XANES at the $\mathrm{L}_{\mathrm{III}}$ edge of the prepared catalysts and the reference foil indicated a higher oxidation state for the uncoated $\mathrm{Pt} / \mathrm{SiO}_{2}$ catalyst, which was also confirmed by the EXAFS containing Pt-O contributions for the $\mathrm{Pt} / \mathrm{SiO}_{2}$ catalyst. The Pt cluster particle size was reduced to $0.9 \mathrm{~nm}$, but the fact that the Pt-Pt distance did not increase for the $\mathrm{Pt} / \mathrm{SiO}_{2}$ catalyst compared the bulk metal foil indicates that oxygen neighbouring atoms are in the outer shell of the Pt clusters only. In contrast, the Pt particles in the coated system were in zero oxidation state, as neighbouring oxygen atoms were not found and the XANES was 
identical to that of bulk Pt. This illustrates that the use of the ionic liquid protects the metal clusters from oxidation under typical sample handling conditions.

Hydrogenation of ethene showed zero order in ethene and first order (concluded from preliminary measurements) in hydrogen in a temperature interval from 30 to $50{ }^{\circ} \mathrm{C}$. This is in perfect agreement with the literature for Pt supported on silica ${ }^{22}$. It is generally accepted that the reaction proceeds via the Horiuti-Polanyi mechanism ${ }^{23}$. According to this mechanism ethene adsorbs associatively on the metal surface, while hydrogen adsorbs dissociatively. The first order in hydrogen points to a nearly simultaneous addition of hydrogen in the rate determining step. It has been shown ${ }^{23}$ that the sites for ethene and hydrogen are not identical, i.e., under the conditions used the adsorption is non-competitive. The zero order in ethene indicates that the surface of the metal particles is essentially covered with ethene. This is remarkable, as the ionic liquid is present in very large excess compared to ethene. In the absence of detailed information on the heat of adsorption of the ionic liquid on metal surfaces, we speculate that the smaller size of ethene and the fact that it can form a di- $\sigma$-sorbed adsorbed state leads to a better stabilization compared with the $\pi$ bonding of the imidazolium ion.

\section{Conclusions}

The detailed analysis of the supported platinum catalysts coated with a thin film of BDiMIm gave an insight to the interactions of the ionic liquid with the oxide support and the metal clusters. The spectroscopy confirmed that the vibrations of the imidazolium ring of the $\mathrm{SiO}_{2}$ supported ionic liquid were less restricted, whereas the viscosity of the ionic liquid increased. This will have a strong impact on the diffusivity of reactants to the active sites, allowing tailoring the selectivity towards certain products. The presence of platinum clusters further modified the electron density of the ionic liquid, which changes the polarity of the ionic liquid within certain limits and can also be used to improve the selectivity. In addition, the complete coverage of the catalyst surface including the metal particles with the ionic liquid protects the catalyst from oxidation, which can be further utilized to protect air sensitive catalysts. The similar catalytic activity of the coated catalyst for ethene hydrogenation at low temperatures shows that the ionic liquid does not block the access of hydrogen or ethane to the active sites. This is important aspect which 
indicates that the interaction of the ionic liquid and the Pt surface is weaker compared to the reactant molecules and therefore, potential transport limitations resulting from a low solubility of reactants did not occur. This opens new possibilities for the selective hydrogenation of unsaturated compounds as the properties of the metal and of the reaction environment can be subtly tuned via the ionic liquid.

\section{Acknowledgements}

The project is funded by the BMBF (promotional reference 03X2012F). The authors are grateful to Max-Buchner-Stiftung for partial support. The authors acknowledge fruitful discussions in the framework of the network of excellence IDECAT. The authors would like to thank HASYLAB, Hamburg, Germany and the Institut Laue-Langevin Grenoble, France for providing beamtime at station X1 for XAFS experiments and at the IN1-BeF spectrometer to record the INS spectra. Xaver Hecht and Martin Neukamm are thanked for the experimental support.

\section{References}

A. Riisager, R. Fehrmann, S. Flicker, R. van Hal, M. Haumann, P. Wasserscheid, Angewandte ChemieInternational Edition, 2005, 44, 815.

2 O. Jimenez, T. E. Muller, C. Sievers, A. Spirkl, J. A. Lercher, Chem. Commun., 2006, 2974.

3 C. Sievers, O. Jimenez, R. Knapp, X. Lin, T. E. Muller, A. Turler, B. Wierczinski, J. A. Lercher, J. Mol. Catal. A: Chem., 2008, 279, 187.

$4 \quad$ H. L. Pelt, J. Brockhus, R. P. J. Verburg, J. J. F. Scholten, J. Mol. Catal., 1985, 31, 107.

5 J.P. Arhancet, M. E. Davis, J. S. Merola, B. E. Hanson, J. Catal., 1990, 121, 327.

6 C. P. Mehnert, E. J. Mozeleski, R. A. Cook, Chem. Commun, 2002, 3010.

T. Welton, Coord. Chem. Rev., 2004, 248, 2459.

R. Atkin, G. G. Warr, J. Am. Chem. Soc., 2005, 127, 11940.

9 C. Sievers, O. Jimenez, T. E. Muller, S. Steuernagel, J. A. Lercher, J. Am. Chem. Soc., 2006, 128, 13990.

A. Wolfson, I. F. J. Vankelecom, P. A. Jacobs, Tetrahedron Lett., 2003, 44, 1195.

H. Hagiwara, Y. Sugawara, K. Isobe, T. Hoshi, T. Suzuki, Org. Lett., 2004, 6, 2325.

Gaussian 03, Revision C.02, M. J. Frisch, G. W. Trucks, H. B. Schlegel, G. E. Scuseria, M. A. Robb, J. R. Cheeseman, J. A. Montgomery, Jr., T. Vreven, K. N. Kudin, J. C. Burant, J. M. Millam, S. S. Iyengar, J. Tomasi, V. Barone, B. Mennucci, M. Cossi, G. Scalmani, N. Rega, G. A. Petersson, H. Nakatsuji, M. Hada, M. Ehara, K. Toyota, R. Fukuda, J. Hasegawa, M. Ishida, T. Nakajima, Y. Honda, O. Kitao, H. Nakai, M. Klene, X. Li, J. E. Knox, H. P. Hratchian, J. B. Cross, V. Bakken, C. Adamo, J. Jaramillo, R. Gomperts, R. E. Stratmann, O. Yazyev, A. J. Austin, R. Cammi, C. Pomelli, J. W. Ochterski, P. Y. Ayala, K. Morokuma, G. A. Voth, P. Salvador, J. J. Dannenberg, V. G. Zakrzewski, S. Dapprich, A. D. Daniels, M. C. Strain, O. Farkas, D. K. Malick, A. D. Rabuck, K. Raghavachari, J. B. Foresman, J. V. Ortiz, Q. Cui, A. G. Baboul, S. Clifford, J. Cioslowski, B. B. Stefanov, G. Liu, A. Liashenko, P. Piskorz, I. Komaromi, R. L. Martin, D. J. Fox, T. Keith, M. A. Al-Laham, C. Y. Peng, A. Nanayakkara, M. Challacombe, P. M. W. Gill, B. Johnson, W. Chen, M. W. Wong, C. Gonzalez, and J. A. Pople, Gaussian, Inc., Wallingford CT, 2004.

13 A. J. Ramirez-Cuesta, Comput. Phys. Commun., 2004, 157, 226.

14 K.V. Klementiev, VIPER for Windows, freeware: http://www.desy.de/ klmn/viper.html. 
15 A. L. Ankudinov, B. Ravel, J. J. Rehr, S. D. Conradson, Phys. Rev. B: Condens. Matter, 1998, 58, 7565.

A. L. Ankudinov, J. J. Rehr, Phys. Rev. B: Condens. Matter, 2000, 62, 2437.

K.V. Klementiev, XANES dactyloscope, freeware: http://www.desy.de/ klmn/xanda.html.

R. E. Benfield, J. Chem. Soc., Faraday Trans., 1992, 88, 1107.

A. Johansson, J. Tegenfeldt, J. Chem. Phys., 1996, 104, 5317.

A. Lauenstein, J. Tegenfeldt, J. Phys. Chem. B, 1997, 101, 3311.

R. Spindler, D. F. Shriver, J. Am. Chem. Soc., 1988, 110, 3036.

R. D. Cortright, S. A. Goddard, J. E. Rekoske, J. A. Dumesic, J. Catal., 1991, 127, 342.

J. Horiuti, M. Polanyi, Trans. Faraday Soc., 1934, 30, 1164 